\title{
OCCURRENCE OF ENTEROHAEMORRHAGIC Escherichia coli IN BUFFALO MEAT
}

\section{Sunita Rani ${ }^{1}$, Y. Singh ${ }^{1}$, B.R. Gulati ${ }^{2}$ and Sandip Kumar Khurana ${ }^{3, *}$}

${ }^{1}$ Department of Veterinary Public Health and Epidemiology, L L R University of Veterinary and animal Sciences, Hisar, Haryana-125 004.

${ }^{2}$ National Research Centre on Equines, Sirsa Road, Hisar, Haryana-125 001

${ }^{3}$ Central Institute for Research on Buffaloes, Hisar, Haryana, India

Received - January 22, 2017; Revision - March 15, 2017; Accepted - April 28, 2017

Available Online - May 12, 2017

DOI: http://dx.doi.org/10.18006/2017.5(2).208.214

\section{KEYWORDS}

Enterohaemorrhagic

E. coli

Buffen

Cytotoxicity

Foodborne pathogen

\begin{abstract}
Enterohaemorragic Escherichia coli (EHEC) is a pathogenic E.coli which causes diarrhea or haemorrhagic colitis in human beings, which may occasionally progress to hemolytic uremic syndrome (HUS). A total of 100 buffalo meat samples (buffen) were processed for finding out the presence of enterohaemorrhagic E. coli (EHEC). Among them, thirty five samples were found positive for $E$. coli (35\%), which yielded 37 isolates belonging to 17 different serogroups. However, one strain remained untypable. Further, out of $37 \mathrm{E}$. coli, nine were confirmed as EHEC and belonged to four different serogroups viz., O10, O68, O111 and O172. All the 9 EHEC strains were cytotoxigenic to Vero-cells. Cytotoxic changes usually appeared at 12 hours post inoculation (hpi) and their intensity increased up to 72 hpi. The important cellular changes recorded were rounding and degeneration of cells followed by detachment of cell sheet and subsequently formation of homogenized cellular masses. Most predominant serotype of EHEC was O111 having 5 isolates (55.6\%) and none of the E. coli isolate belonged to serotype O157. The prevalence of a wide range of EHEC serogroups in buffalo meat may be due to contamination during or after slaughter and may serve as major source of human infections.
\end{abstract}

* Corresponding author

E-mail: sandipkk2003@yahoo.co.in (Sandip Kumar Khurana)

Peer review under responsibility of Journal of Experimental Biology and Agricultural Sciences.

Production and Hosting by Horizon Publisher India [HPI] (http://www.horizonpublisherindia.in/).

All rights reserved.
All the article published by Journal of Experimental Biology and Agricultural Sciences is licensed under a Creative Commons Attribution-NonCommercial 4.0 International License Based on a work at www.jebas.org.

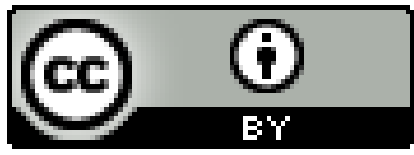




\section{Introduction}

Over the last few decades, enterohaemorrhagic Escherichia coli (EHEC) have emerged as an important food-borne enteropathogen of humans, apart from others like Salmonella, Campylobacter, Listeria monocytogenes; Aercobacter (Dhama et al., 2013a; Dhama et al., 2013b; Dhama et al., 2015). Various serotypes have been reported to cause serious episodes of haemorrhagic colitis (HC) leading to bloody diarrhoea in man, in which meat and meat products served as the vehicle (Cameron et al., 1995; Dhama et al., 2013b; Sethulekshmi et al., 2016). The most notorious serotype of EHEC responsible for $85-95 \%$ cases of haemorrhagic colitis, hemolytic uremic syndrome (HUS) and other human illnesses is $E$. coli O157 (Fernandez, 2008; Kiranmayi \& Krishnaiah, 2010; Thomas \& Elliott, 2013; Flamy et al., 2014). The other non-0157 serotypes that cause remaining 5-15\% human diseases are: O10, 022, O26, 028, 039.O55, O68, 0103, O111, O128, O145 andO172 (Gyles, 1994).

Bovines are perceived to be their natural reservoirs. Transmission generally occurs through soiling of carcass with animal faeces. Illness in humans is primarily caused by consumption of contaminated undercooked food and meat products, and lead to significant economical losses worldwide (Welinder-Olsson \& Kaijser, 2005; Scharff, 2012; Sethulekshmi et al., 2016). The infection had occurred worldwide and serotypes may vary in different geographies (Strachan et al., 2015). Cattle, sheep, sometimes goats are major reservoirs of EHEC, but remain asymptomatic (Sethulekshmi et al., 2016). It may be found in bison, deer and occasionally in pigs, camels, horses, cats, dogs, bear, rats, raccoons, opossums (Navarro-Gonzalez et al., 2015). It may also be detected from several wild and domesticated birds. Present communication describes the prevalence of enterohaemorrhagic $E$. coli in meat of slaughtered buffaloes.

\section{Materials and Methods}

One hundred samples of buffalo-meat (buffen) were collected aseptically from the MCD slaughter house, Delhi, India. These meat samples included mainly inner thigh or neck muscles and were collected aseptically in approximately $25 \mathrm{~g}$ amount in sterile plastic cups. The samples were then transported to laboratory on dry ice and kept in refrigerator for overnight before processing.

Preliminary isolation of E. coli from buffalo-meat samples was done according to the method described by Bennett et al. (1995) using modified tryptone soya broth (mTSB) as enrichment medium and cefixime-tellurite sorbitol MacConkey agar (CT-SMAC) as selective medium. For this, Meat sample were homogenized in $25 \mathrm{ml}$ of mTSB and transferred to $200 \mathrm{ml}$ of mTSB and incubated at $37^{\circ} \mathrm{C}$ for $18-24 \mathrm{~h}$. The enriched culture was further inoculated on CT-SMAC agar plates and incubated at $37^{\circ} \mathrm{C}$ for $18-24 \mathrm{~h}$. The plates were examined for presence of various types of colonies such as circular colonies with either of uniform purple color, purple color with dark centre, light pink colony or colorless colony of $3-5 \mathrm{~mm}$ in diameter. Two to three representative colonies of each type were picked up and considered as presumptive E. coli. The picked up colonies were then purified by sub culturing thrice on CT-SMAC agar plates. The purified cultures of E. coli were maintained on TSB agar slants for further identification and characterization.

Presumptive E. coli isolates were identified as per methods described by Edwards \& Ewing (1972). To identify the enterohaemorrhagic E. coli (EHEC) O157 organisms or non-O157 EHEC, these cultures were further subjected to various types of tests viz., urease reaction, motility, hemolysin production and $\beta$ glucuronidase reaction by growing on modified sorbitol macConkey agar supplemented with 4-methyl umbelliferyl- $\beta$-Dglucuronide (MUG) substrate (Fujisawa et al., 2000). Their cytotoxigenic potential on vero cell was also assayed as per the method described by Konowalchuk et al. (1977) keeping standard strain of E. coli $\mathrm{O} 157$ as a positive control. To examine the verocytotoxigenicity, cell-free culture filtrate (CFCF) was prepared as described by Konowalchuk et al. (1977) by growing the organism in brain heart infusion broth for $18 \mathrm{~h}$ at $37^{\circ} \mathrm{C}$ on a rotary shaker $(200 \mathrm{rpm})$. Subsequently the broth culture was centrifuged at $10,000 \mathrm{rpm}$ for $30 \mathrm{~min}$ at $4^{\circ} \mathrm{C}$ (Remi, India) and supernatant was filtered through membrane filter $(0.45 \mu \mathrm{m})$. After checking sterility, sterile filtrate (CFCF) were stored at $-20^{\circ} \mathrm{C}$ and tested for cytotoxicity within a week on monolayers of Vero cells grown in 24 well tissue culture plate in minimum essential medium (MEM) supplemented with $8 \%$ foetal calf serum. All the identified cultures of E. coli were sent to the National Salmonella and Escherichia coli centre, Central Research Institute, Kasauli (Himachal Pradesh, India) for serotyping.

\section{Results and Discussion}

Among the studied 100 buffalo-meat samples, 35 samples were found positive for E. coli (35\%), which yielded 37 isolates belonging to 16 different serogroups. All these 37 isolates were Gram negative motile rods and were positive for catalase, indole and methyl red tests but negative for oxidase, Voges-Proskauer and citrate tests. The isolates fermented lactose, sucrose and sorbitol but gave variable results for decarboxylation of lysine, arginine and ornithine. On Eosin methylene blue (EMB) agar, all the isolates exhibited metallic green sheen. All 37 isolates of E. coli were negative for urease reaction and positive for motility and $\beta$ glucuronidase reaction. Only $9 \mathrm{E}$. coli isolates were positive for hemolysin production. The results of sugar fermentation and other biochemical reactions are in agreement with the findings of Ali et al. (1998) and Collins \& Boitumelo (2014).

Based on $\mathrm{O}$ antigen, out of 37 isolates, 34 were typed into 16 serogroups, while 2 were rough strains and one remained untypable. The serogroups to which these $E$. coli isolates belonged were: O8, O9, O10, O25, O27, O43, O48, O60, 068, O70, O73, O78, O100, O109, O111, O172 and rough (Table 1). Most predominant serogroup among typable isolates was O111 (13.5\%) which is considered one of the important virulent serogroup as described by Baljer \& Wieler 1999. 
Table 1 Distribution of different serogroups of $E$. coli isolates in buffalo-meat

\begin{tabular}{|llccc|}
\hline Sr.No. & Serogroups & No. of serotypes & No. of isolates in each serotype (\%) & Total no of isolates \\
\hline $\mathbf{1}$ & O111 & 1 & $5(13.51)$ & 5 \\
\hline $\mathbf{2}$ & O60 & 1 & $4(10.81)$ & 4 \\
\hline $\mathbf{3}$ & O8,O70,O78 & 3 & $3(8.11)$ & 9 \\
\hline $\mathbf{4}$ & O9,O25,O48,O172, O109, rough & 6 & $2(5.40)$ & 12 \\
\hline $\mathbf{5}$ & 010, 027, 043, O68, O73,O100 Untypable & 6 & $1(2.70)$ & 7 \\
\hline & Total & 17 & - & 37 \\
\hline
\end{tabular}

During Vero cell cytotoxicity assay, the uninoculated control Vero cells did not show any appreciable change (Figure 1). However, Vero cells inoculated with CFCF of tested $E$. coli isolates showed a variable degree of cytopathic changes. Cytotoxic changes usually appeared at $12 \mathrm{hpi}$ and their intensity increased up to $72 \mathrm{hpi}$. The important cellular changes recorded were rounding and degeneration of cells followed by detachment of cell sheet and subsequently formation of homogenized cellular masses. The CFCFs capable of producing rounding and clumping of Vero cells involving about $25 \%$ of cell sheet within $72 \mathrm{hrs}$ were designated moderately cytotoxic (Figure 2) while the rounding of Vero cells along with cellular degeneration and detachment forming large gaps in cell sheet within this period were considered as highly cytotoxic (Figure 3). Among 37 isolates, 17 E. coli isolates were positive for verocytotoxigenicity and rest were negative. Out of these 17 verocytotoxigenic E. coli, eight isolates belonging to serogroups $\mathrm{O} 25, \mathrm{O} 73, \mathrm{O} 78$ and rough strain were found moderately verocytotoxigenic while nine isolates of serogroup O10, O68, O111 and $\mathrm{O} 172$ as highly verocytotoxigenic.

Based on these findings, 9 isolates $(24.3 \%)$ belonging to four different serogroups viz. O10, O68, O111 and O172 were categorized as enterohaemorrhagic E. coli (EHEC). Predominant serogroup of EHEC was O111 representing 5 isolates (55.6\%). Two isolates belonged to serogroup O172 while 1 each to O68 and $\mathrm{O} 10$ (Table 2). None of the isolates belonged to EHEC O157 and all the 37 isolates were negative for urease and positive for motility and $\beta$-glucuronidase reaction.

In this study, out of 37 obtained E. coli isolates, 9 (24.3\%) were identified as non-O157 EHEC. Earlier, the epidemiological studies on worldwide occurrence of EHEC in beef, revealed the detection rate up to $36.4 \%$ in Southern Ontario, Canada (Clarke et al., 1994), 23-25\% in Seattle, Washington (Samadpour et al., 1994), 17\% in London (Willshaw et al., 1993) and, $14.1 \%$ in Netherlands (Heuvelink et al., 1996). Further, Suthienkul et al. (1990) isolated EHEC isolates from 9\% market beef and 8-28\% from fresh beef specimens in a slaughterhouse. Similarly, Sethulekshmi et al., (2016) had reported $15.68 \%$ prevalence rate of EHEC from beef samples. Thus the results of the above epidemiological investigations further strengthen the finding of present study. However, Manandhar et al. (1997) found only 3\% EHEC in raw beef in Australia. The lower occurrence of EHEC in meat as recorded in Australia may be due to variation in geographical conditions. Similarly, Rahimi et al. (2012) found $4.7 \%$ of 295 meat samples positive for E. coli $\mathrm{O} 157$, and highest prevalence was found in beef samples $(8.2 \%)$, which was followed by water buffalo (5.3\%), sheep (4.8\%), camel $(2.0 \%)$ and goat (1.7\%). Jure et al. (2015) have isolated and characterized seven E. coli $\mathrm{O} 157$ isolates from cattle and meat products with a prevalence of $1.4 \%$ from Tucuman Province of Argentina.

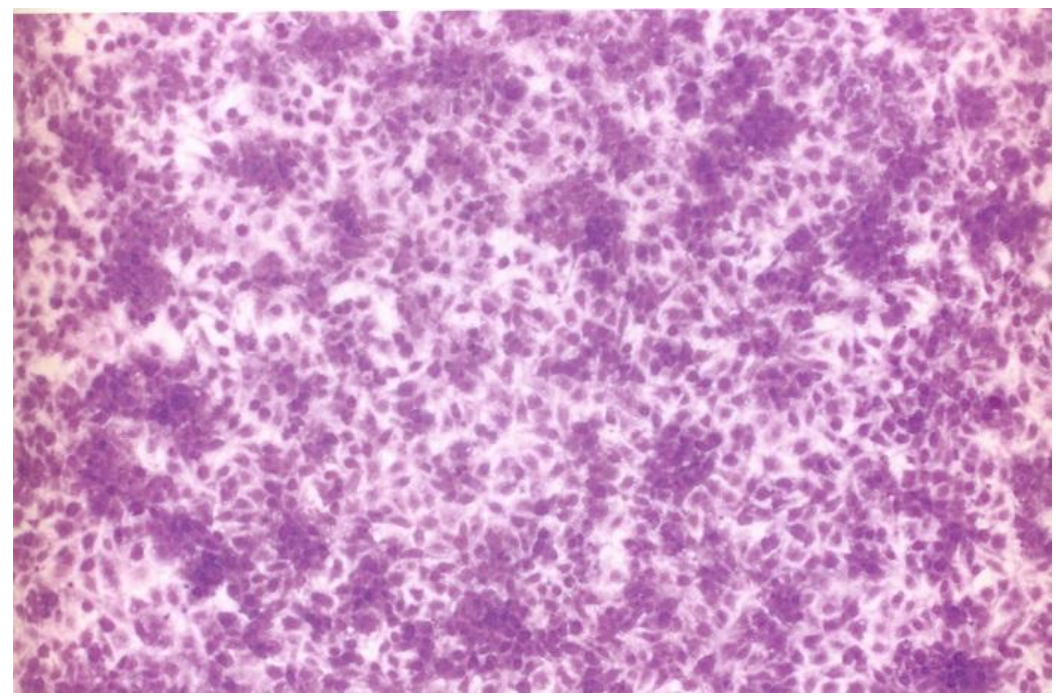

Figure 1 Vero cells inoculated with sterile BHI broth showing no appreciable changes at 48 hpi on staining with crystal violet (cv) x 40

Journal of Experimental Biology and Agricultural Sciences

http://www.jebas.org 
Table 2 Distribution of EHEC serotypes in buffalo meat

\begin{tabular}{|lccc|}
\hline Sr. No. & Sero groups & No. of meat samples positive & No. of isolates in each serotype (\%) \\
\hline $\mathbf{1}$ & O111 & 5 & $5(55.56)$ \\
\hline $\mathbf{2}$ & $\mathrm{O} 172$ & 2 & $2(22.22)$ \\
\hline $\mathbf{3}$ & $\mathrm{O} 68$ & 1 & $1(11.11)$ \\
\hline $\mathbf{4}$ & $\mathrm{O} 10$ & 1 & $1(11.11)$ \\
\hline
\end{tabular}

The findings of present study are quite comparable to the previous findings, as $E$. coli in raw meat of buffalo has been earlier reported to be $43.75 \%$ (Banerjee et al., 2000). In another study, E. coli in buffalo-meat revealed 24.83\% (Hazarika, 2002). However, Rathore (2000) reported only $9.4 \%$ occurrence in raw buffalo-meat. The prevalence of a wide range of EHEC serogroups in meat may be due to contamination during or after slaughter and may serve as major source of human infections.

Most predominant serogroup was $\mathrm{O} 111(13.5 \%)$ and it was followed by $\mathrm{O} 60$ (10.81\%) and O8, O70, O78 (8.11\% each). None of the E. coli isolate belonged to serogroup O157. During an investigation of food associated outbreak of HUS in South Australia, Cameron et al. (1995) recorded the isolation of E. coli O111 serotype from fermented meat which further strengthen the present findings. Isolation of EHEC of serogroups of O26, O111 and $\mathrm{O} 157$ has been reported from beef meat in Chile and Australia (Borie et al., 1997; Desmarchelier, 1997) Similarly, Banerjee et al. (2000) reported the isolation of verotoxigenic E. coli including O8,
O68, O84 and O88 serotypes from buffalo-beef but not a single strain belonging to serotype O157. Similar observations were made by earlier workers regarding the absence of $\mathrm{O} 157$ from meat and their products (Smith et al., 1998; Sethulekshmi et al., 2016). However, Doyle \& Schoeni (1987) reported the isolation of O157 from 1.5-3.7\% samples of ground beef. Further, Hazarika (2002) reported the occurrence of 08, O10, O25, O73 and O109 along with rough serotypes from meat and meat products of buffalo and cattle. Similarly, detection of O8, O43, O172 and rough strains of E. coli has been recorded from beef by Schurman et al. (2000).

During the present study the higher incidence of EHEC in raw buffalo meat may be as a result of soiling of the carcass with faecal material due to lack of hygienic conditions during slaughter. Modern techniques for reduction of microbial contamination during slaughter and processing of meat may reduce the risk (Saeedi et al., 2017). Meat should be property cooked at proper temperature to destroy E.coli. Good hygienic practices by consumers to prevent contamination are of great importance.

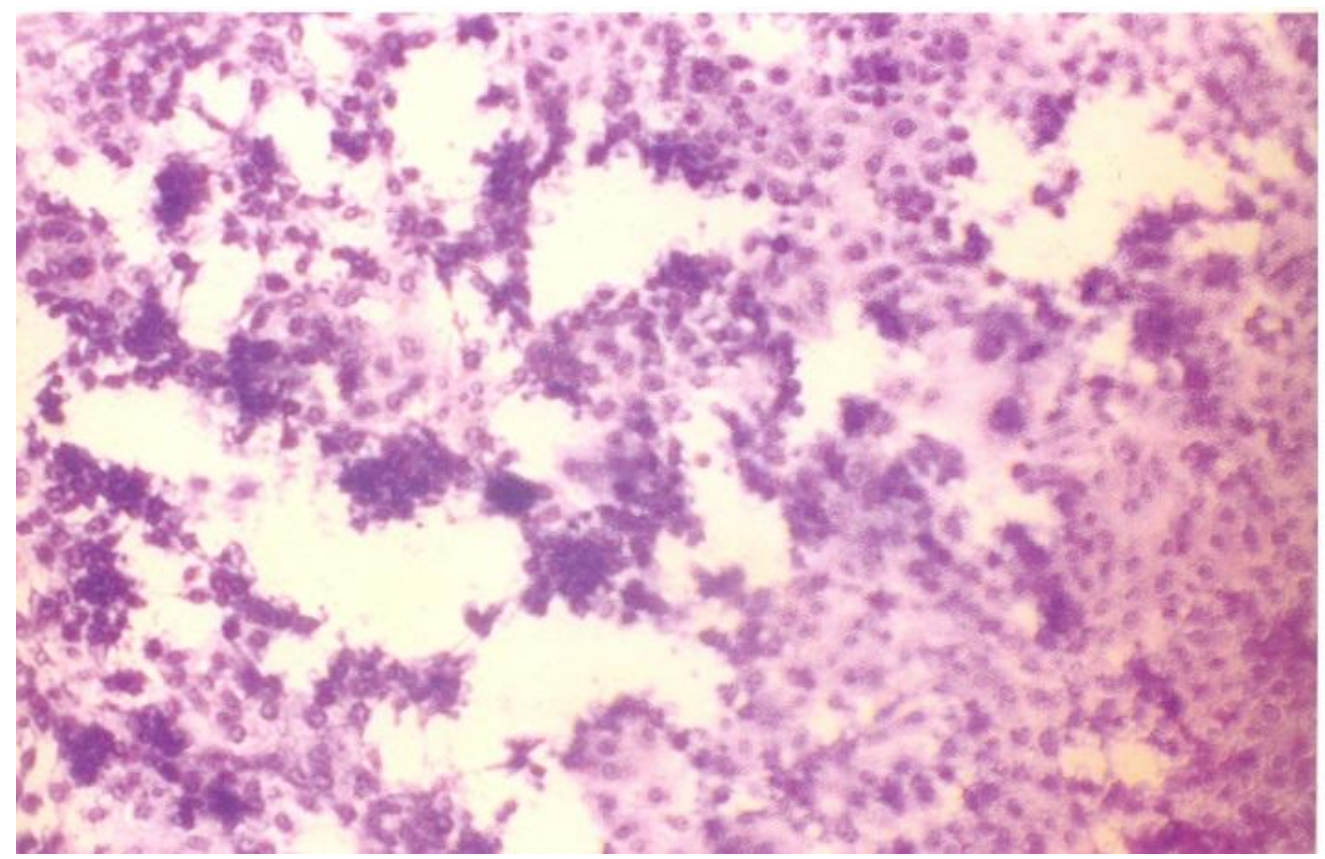

Figure 2 Vero cells showing rounding up to $25-50 \%$ of cell sheet and clumping of cells (++) on exposure to CFCS of E. Coli O111 at 24 hpi on staining with crystal violet (cv) $\mathrm{x} 40$

Journal of Experimental Biology and Agricultural Sciences http://www.jebas.org 


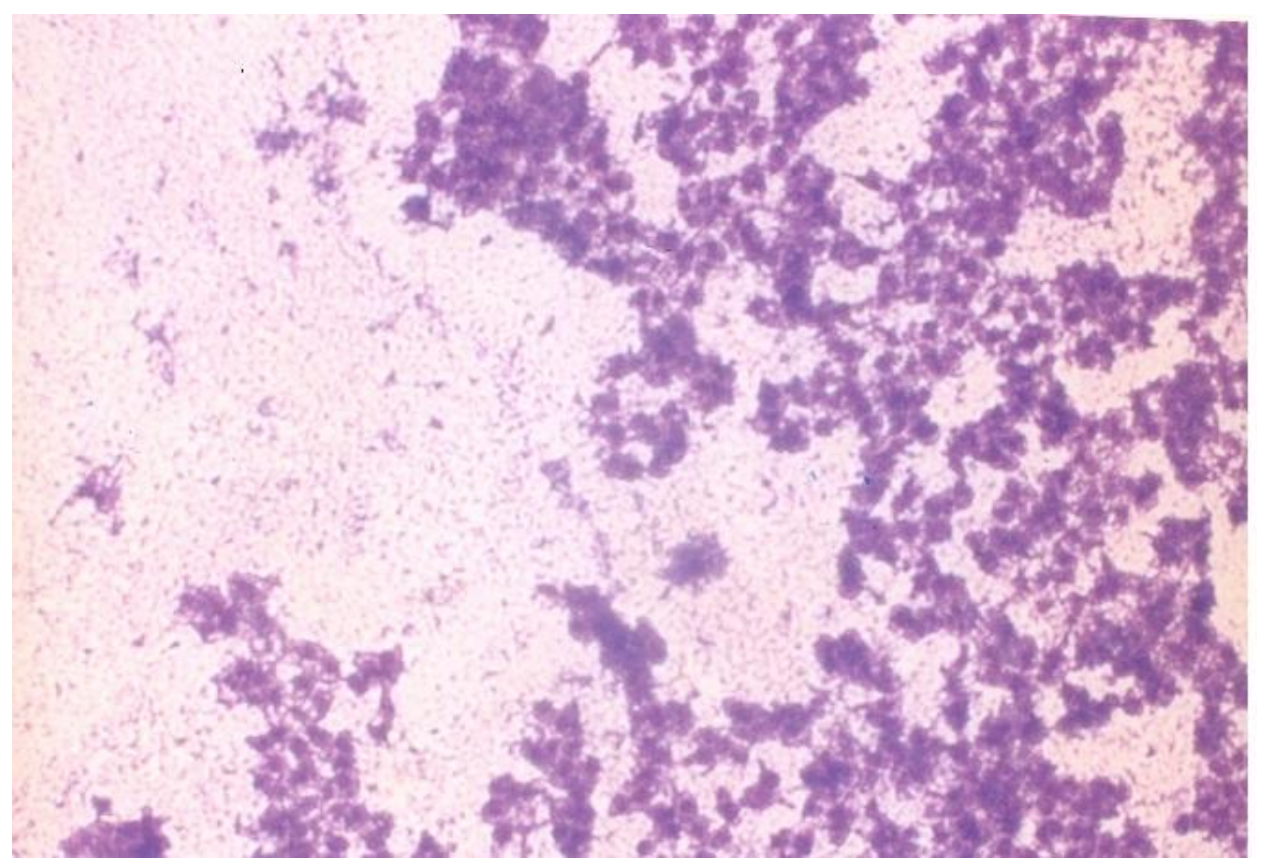

Figure 3 Vero cells showing detachment, degeneration and cellular masses $(+++)$ on exposure to CFCS of E. Coli 0111 at 48 hpi on staining with crystal violet (cv) $\mathrm{x} 40$

\section{Conflict of interest}

Authors would hereby like to declare that there is no conflict of interests that could possibly arise.

\section{References}

Ali MY, Rahman MT, Islam MA, Choudhury KA, Rahman MA (1998) Characterization of E. coli isolates of human and animal origin. Progressive Agriculturist 9: 221-224.

Banerjee R, Kapoor KN, Agarwal RK, Ghatak S (2000) Verotoxin producing Escherichia coli (VTEC) in foods of animal origin. Food Science and Technology 38: 82-84.

Baljer G, Wieler LH (1999) Enterohaemorrhagic E. coli (EHEC) -Recent information on a new medically important zoonotic agent. Lohmann Information 22:21-26.

Bennett AR, MacPhee S, Betts RP (1995) Evaluation of methods for the isolation and detection of Escherichia coli 0157 in minced beef. Letters in Applied Microbiology 20: 375180.

Borie C, Monreal Z, Guerrero P, Sanchez ML, Maritinez J, Arellano C, Prads V (1997) Prevalence and characterization of enterohaemorrhagic Escherichia coli isolated from healthy cattle and pigs slaughtered in Santiago, Chile. Archivos de Medicine Veterinaria 29: 205-212.
Cameron S, Walker C, Beers M, Rose N, Anear E (1995) Enterohaemorrhagic Escherichia coli outbreaks in South Australia associated with consumption of mettwurst. Communicable Disease Intelligence 19: 70-71.

Clarke RC, Wilson JB, Read SC, Renwick S, Rahn K, Johnson RP, Alves D, Karmali MA, Lior H, McEwen SA, Spika J, Gyles CL (1994) Verocytotoxin-producing Escherichia coli (VTEC) in food chain: Preharvest and processing perspectives. In: Karmali MA,

Goglio AG (Eds.), Recent advances in verocytotoxinproducing Escherichia coli infections. Elsevier Science, B.V., Amsterdam. Pp: 17-24.

Collins NA, Boitumelo IM ((2014) Isolation of enterohaemorrhagic Escherichia coli O104 strains from raw meat products in the north west province, South Africa. Journal of Food and Nutrition Research 2: 288-293.

Desmarcheller PM (1997) Enterohaemorrhagic Escherichia coli : The Australian perspective. Journal of Food Protection 60: $1447-1450$.

Dhama K, Rajagunalan S, Chakraborty S, Verma AK, Kumar A, Tiwari R, Kapoor S (2013a) Food-borne pathogens of animal origin-diagnosis, prevention, control and their zoonotic significance: a review. Pakistan Journal of Biological Sciences 16: $1076-1085$

Journal of Experimental Biology and Agricultural Sciences http://www.jebas.org 
Dhama K, Chakraborty S, Barathidasan R, Tiwari R, Rajagunalan S, Singh SD (2013b) Escherichia coli, an economically important avian pathogen, its disease manifestations, diagnosis and control, and public health significance: a review. Research opinions in animal \& veterinary sciences $3: 179-194$.

Dhama K, Karthik K, Tiwari R, Shabbir MZ, Barbuddhe S, Malik SV, Singh RK (2015) Listeriosis in animals, its public health significance (food-borne zoonosis) and advances in diagnosis and control: A comprehensive review. Veterinary Quarterly 35:211-235.

Doyle MP, Schoeni JL (1987) Isolation of Escherichia coli 0157:H7 from retail fresh meats and poultry. Applied and Environmental Microbiology 53: 2394-2396

Edwards R, Ewing WH (1972) Identification of Enterobacteriaceae, $3^{\text {rd }}$ edn, Burgess Publishing Co., Minnoesota.

Fernandez TF (2008) E. coli O157:H7. Veterinary World 1: 83-87.

Flamy A Jacob, Latha C, Sunil B (2014) Isolation and identification of enterohaemorrhagic E. coli in raw meat. International Journal of Scientific and research Publications 4:1-2.

Fujisawa T, Sata S, Aikawa K, Takahashi T, Yamai S, Shimada T (2000) Modification of sorbitol Mac Conkey medium containing cefixime and tellurite for isolation of Escherichia coli O157: H7 from radish sprouts. Applied Environmental Microbiology 66: 3117 - 3118.

Gyles CL (Eds) (1994) Escherichia coli in domestic animals and humans. CAB International, U.K.

Hazarika (2002) Verotoxic E. coli, detection in buffalo meat and survivability in red meat gravy added with preservatives. $\mathrm{PhD}$ Thesis submitted to Deemed University, IVRI, Izatnagar.

Heuvelink AE, Wernars K, Enne De Boer (1996) Occurrence of Escherichia coli G157 and other verocytotoxin-producing $E$. coli in retain raw meats in the Netherlands. Journal of Food Protection 59: 1257-1272.

Jure MA, Condori MS, Perz Terrazzino G, Catalan MG, Lopez Campo A, Zolezzi G, Chinen I, Rivas M, Castiloo M (2015) Isolation and characterization of Escherichia coli $\mathrm{O} 157$ in bovine meat products and cattle in province of Tucuman. Revista Argentina de Microbiologia 47: 125-131.

Kiranmayi CH, Krishnaiah N (2010) Detection of Escherichia coli $\mathrm{O} 157: \mathrm{H} 7$ prevalence in foods of animal origin by cultural methods and PCR technique. Veterinary World 3:13-16.
Konowalchuk J, Speirs JI, Starvic S (1977) Vero response to a cytotoxin of Escherichia coli. Infectection and Immunity 18: 775.

Manandhar R, Bettiol SS, Bettelheim KA, Goldmid J (1997) Isolation of verotoxigenic Escherichia coli from the Tasmanian environment Comparative Immunology Microbiology and Infectious Diseases 20: 271-275.

Navarro-Gonzalez N, Porrero MC, Mentaberre G, Serrano E, Mateos A, Cabal A, Domínguez L, Lavín S (2015) Escherichia coli O157:H7 in wild boars (Sus scrofa) and Iberian ibex (Capra pyrenaica) sharing pastures with free-ranging livestock in a natural environment in Spain. Veterinary Quarterly 35: $102-6$.

Rahimi E, Kazemeini HR, Salajegheh M (2012) E. coli O157: H7/NM prevalence in raw beef, camel, sheep, goat and water buffalo meat Fars and Khuzestan provinces, Iran. Veterinary Research Forum 3: 15-17

Rathore RS (2000) Studies on enterohaemorrhagic Escherichia coli with special reference to detection of virulence genes. Ph.D. Thesis submitted to Deemed University, IVRI, Izatnagar.

Saeedi P, Yazdanparast M, Behzadi E, Salmanian AH, Mousavi SL, Nazarian S, Amani J (2017)_A review on strategies for decreasing E. coli $\mathrm{O} 157: \mathrm{H} 7$ risk in animals. Microbial Pathogenesis 103: 186-195.

Samadpour M, Ongerth JE, Liston J, Tran N, Nguyen D, Whittam TS, Wilson RA, Tarr PI (1994) Occurrence of Shigalike toxin-producing Escherichia coli in retail fresh seafood, beef, lamb, pork, and poultry from grocery stores in Seattle, Washington. Applied and Environmental Microbiology 60: 1038-1040.

Scharff RL (2012) Economic burden from health losses due to foodborne illness in the United States. Journal of Food Protection 75: 123-131.

Schurman RD, Hariharan H, Heaney SB, Rohn K (2000) Prevalence and characteristics of shiga toxin producing Escherichia coli in beef cattle slaughtered in Prince Edward Island. Journal of Food Protection 63: 1583.

Sethulekshmi C, Latha C, Sunil B (2016) Occurrence of enterohaemorrhagic E. coli in raw meat samples in Kerala. International Journal of Advanced Research in Biological Sciences 3:220-222.

Smith HR, Rowe B, Adak GK, Relly WJ (1998) Shiga toxin (verocytotoxin) producing Eschrechia coli in the united kingdom. In: Kaper LB, O’Brien AD (Eds.) Eschrechia coli O157:H7 and other Shiga toxin producing E.coli strains, Press Washington, DC, Pp. 49-58.

Journal of Experimental Biology and Agricultural Sciences http://www.jebas.org 
Strachan NJ, Rotariu O, Lopes B, MacRae M, Fairley S (2015) Whole genome sequencing demonstrates that geographic variation of Escherichia coli O157 genotypes dominates host association. Scientific Reports 5: 14145.

Suthienkul O, Brown JE, Seriwatana J, Tienthongdee, S, Sastravaha S, Echeverria P (1990) Shiga like toxin producing Escherichia coli in retain meats and cattle in Thailand. Applied and Environmental Microbiology 56: 1135-1139.

Thomas DE, Elliott EJ (2013) Interventions for preventing diarrhea associated hemolytic uremic syndrome: systematic review. BMC Public Health 13: 799.
Welinder-Olsson C, Kaijser B (2005) Enterohemorrhagic Escherichia coli (EHEC). Scandinavian Journal of Infectious Diseases 37: 405-16.

Willshaw GA, Smith HR, Roberts D, Thirwell J, Cheasty T, Rowe B (1993) Examination of raw beef products for the presence of verocytotoxin-producing Escherichia coli, particularly those of serogroup 0157. Journal of Applied Bacteriology 75: 420-426. 